\title{
ANÁLISE DA VIABILIDADE ECONÔMICA DA CADEIA PRODUTIVA DO BIODIESEL: O CASO DA SOJA NA BAHIA
}

\section{ECONOMIC EVALUATION ANALYSIS OF THE BIODIESEL PRODUCTIVE CHAIN: THE SOYBEAN CASE IN BAHIA}

\author{
Adriana Leiras ${ }^{1}$; Silvio Hamacher ${ }^{2}$; Luiz Felipe Scavarda ${ }^{3}$ \\ Departamento de Engenharia Industrial (DEI) - Núcleo de Excelência em Otimização (NEXO) \\ ${ }^{1}$ Catholic University of Rio de Janeiro - PUC-Rio - Rio de Janeiro - Brasil \\ aleiras@aluno.puc-rio.br \\ ${ }^{2}$ Catholic University of Rio de Janeiro - PUC-Rio - Rio de Janeiro - Brasil hamacher@puc-rio.br \\ ${ }^{3}$ Catholic University of Rio de Janeiro - PUC-Rio - Rio de Janeiro - Brasil lfscava@puc-rio.br
}

\begin{abstract}
Resumo
As energias renováveis vêm ganhando muita importância no cenário político e econômico mundial. Apesar da questão do biodiesel estar sendo amplamente investigada, as características regionais de produção ainda não foram suficientemente abordadas. Assim, este artigo analisa a viabilidade econômica da cadeia produtiva do biodiesel produzido a partir do óleo de soja na Bahia, com base em um modelo de simulação desenvolvido pelos autores. No total foram simulados 13 cenários para a produção do biodiesel. A análise dos resultados aponta para uma grande competitividade dessa produção na Bahia.
\end{abstract}

Palavras-chave: biodiesel; cadeia produtiva; avaliação econômica; soja.

\section{Introdução}

As energias renováveis são consideradas uma importante fonte de energia em muitos países, mas em uma escala global menos de $15 \%$ da energia consumida no mundo é renovável (LUND, 2007). Entre as energias renováveis pode-se destacar: a solar (fotovoltaica e térmica), o biogás (de lixo, esterco ou esgoto), a biomassa (restos agrícolas, serragem, biodiesel, álcool e óleos in natura), a eólica e as centrais hidrelétricas. A biomassa é a forma mais comum de energia renovável (McKENDRY, 2002) e corresponde a cerca de 10\% do consumo total de energia no mundo (ANSELMO FILHO e BADR, 2004).

O Brasil possui grande destaque na produção de combustíveis a partir da biomassa. Desde a década de 1970 o país tem incentivado o desenvolvimento de biocombustíveis para o setor de transportes. O programa nacional do álcool (PROALCOOL) foi estabelecido em 1975 e é hoje 
apontado como um grande sucesso com desdobramentos sociais, ambientais e econômicos (GOLDEMBERG et al., 2004). Atualmente, o Brasil possui uma nova oportunidade tecnológica e estratégica na utilização de biomassa: a produção de biodiesel. O biodiesel é um combustível derivado de óleos vegetais (sejam eles novos ou usados) e de gordura animal (DEMIRBAS e BALAT, 2006). Este artigo se concentra na produção do biodiesel a partir de óleos vegetais. Algumas fontes para extração de óleo são: baga da mamona, polpa do dendê, semente de girassol, caroço de algodão, semente de canola, grão de soja e outros vegetais em forma de sementes, amêndoas ou polpas (PARENTE, 2003).

O biodiesel pode ser usado puro ou misturado ao diesel de petróleo em diversas proporções. O Art. 2o, Lei nº 11.097, de 13.01.2005, determina a introdução do biodiesel na matriz energética brasileira, fixando em 5\% em volume (B5) o percentual mínimo obrigatório de adição de biodiesel ao óleo diesel comercializado ao consumidor final em qualquer parte do território nacional. O prazo para aplicação do disposto no caput deste artigo é de 8 anos após a publicação da Lei, sendo de 3 anos o período, após a publicação da Lei, para se utilizar um percentual mínimo obrigatório intermediário de $2 \%$ em volume - B2 (MCT, 2005).

Dessa forma, a principal contribuição deste trabalho é uma análise da transição de estudos pontuais, voltados a técnicas de produção ou transformação, para um cenário agroindustrial que permita a produção de 800 milhões de litros de biodiesel em 2008 e 2 bilhões de litros de em 2013 conforme os cálculos do governo federal - para atender à Lei $\mathrm{n}^{\mathrm{o}}$. 11.097. Nesse contexto, os objetivos deste artigo são: analisar a cadeia produtiva do biodiesel a partir do óleo vegetal de soja; e analisar a viabilidade desta cadeia na Bahia com base em um modelo de simulação desenvolvido pelos autores.

A delimitação à cadeia da soja deve-se à importância desta oleaginosa para a economia brasileira. A capacidade de extração de óleo de soja no Oeste da Bahia é de cerca de 400 milhões de litros de óleo/ano. Como a proporção entre a produção do biodiesel e o consumo de óleo vegetal é de cerca de 1:1, esta capacidade atenderia 50\% da demanda brasileira de B2 em 2008. Assim, justifica-se a escolha do estado da Bahia para aplicação da simulação.

As próximas seções apresentam: a cadeia produtiva do biodiesel; a metodologia de pesquisa adotada; a estrutura do modelo de simulação; a cadeia produtiva da soja na Bahia; os dados utilizados no modelo de simulação; os resultados obtidos e as principais conclusões desenvolvidas pelos autores desse artigo.

\section{Cadeia produtiva do biodiesel}


Os principais elos da cadeia do biodiesel derivado de óleos vegetais são: a produção do grão, a extração do óleo, a produção do biodiesel, a distribuição e a revenda ao consumidor.

O biodiesel é mais comumente produzido através do processo de transesterificação, que consiste na reação química de um óleo vegetal com um álcool na presença de um catalisador, usualmente hidróxido de sódio ou de potássio (FERNANDO et al., 2007). Como resultado, obtémse ácidos graxos, glicerina e biodiesel (éster metílico ou etílico, conforme o álcool utilizado metanol ou etanol, respectivamente) (MEIRELLES, 2003). A glicerina é um co-produto de alto valor que deve ser considerado na analise econômica da cadeia do biodiesel (ROZAKIS e SOURIE, 2005).

O biodiesel produzido será inevitavelmente inserido na logística dos combustíveis. Assim, terá de ser transportado para os locais de estocagem de diesel das grandes distribuidoras de produtos refinados, onde será misturado ao mesmo.

\section{Metodologia da pesquisa}

Para realizar o estudo de caso, foi feita uma triangulação de métodos que inclui investigação documental e levantamentos de percepções por meio de questionários, entrevistas para a coleta de dados e visitas in loco com observação direta, conforme esquematizado na Figura 1.

Figura 1 - Triangulação de Métodos

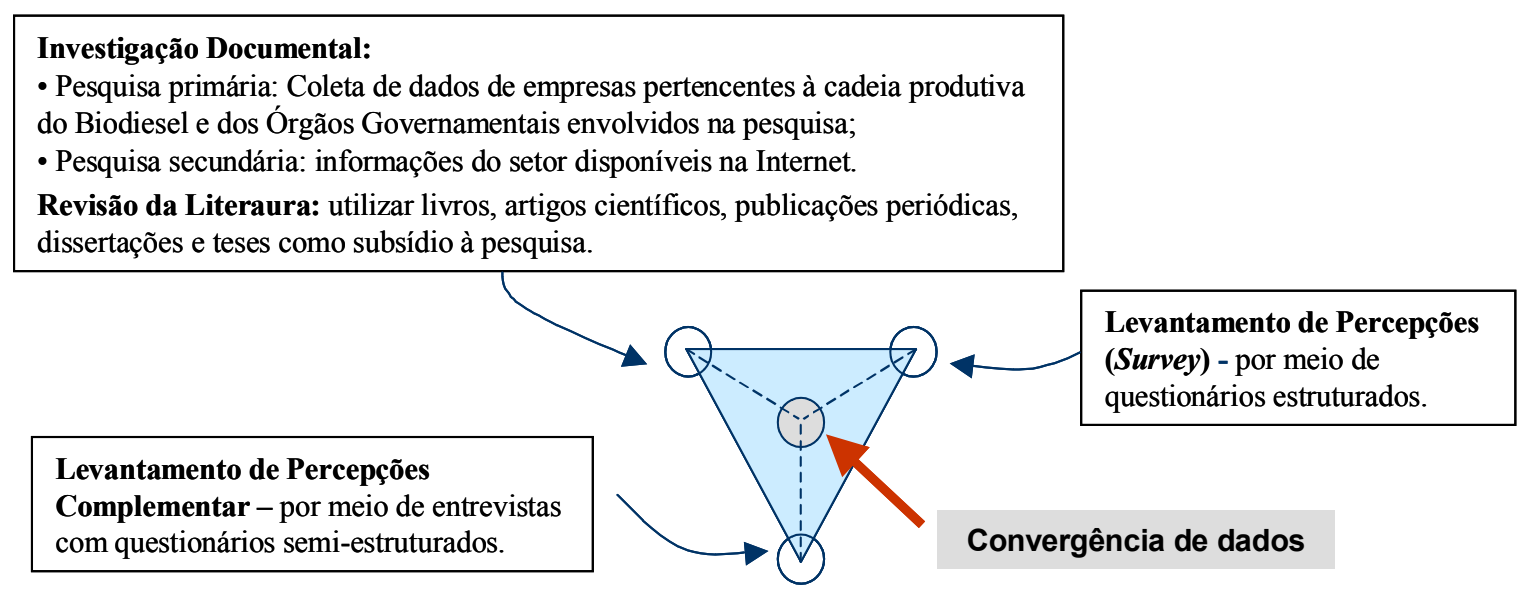

Fonte: Yin, 2005

A partir das informações obtidas pelo método de triangulação foi proposto um modelo para simulação da cadeia produtiva do biodiesel. A metodologia é representada na Figura 2. 


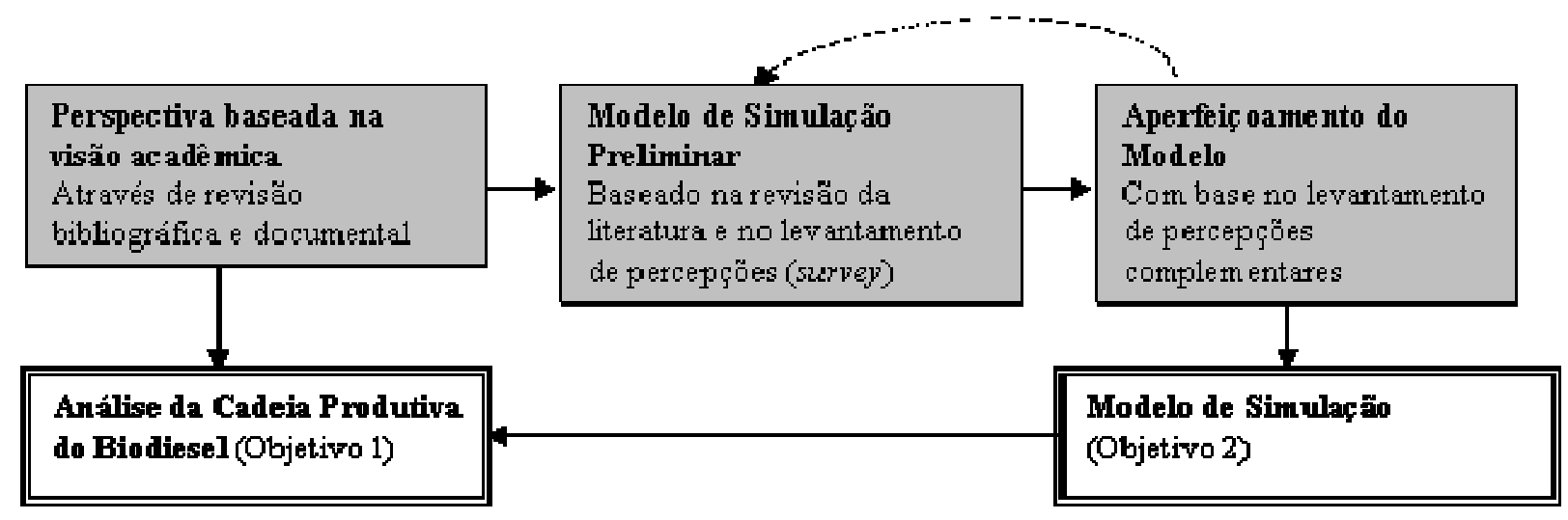

Baseado em Menon et. al., 1999

O formato final do modelo de simulação foi determinado a partir de diversas interações com empresários/ especialistas da área do agronegócio e de biocombustíveis. Dessa forma foi desenvolvido um modelo que, além de ser coerente com a perspectiva acadêmica, é uma ferramenta útil aos empresários e pesquisadores. Para a coleta de dados primários, foram aplicados questionários a empresários e pesquisadores da área por meio de amostragem não probabilística. A inserção dos respondentes da pesquisa se deu por meio de 27 entrevistas. Os entrevistados pertencem aos seguintes elos da cadeia: 5 da produção agrícola, 4 da extração do óleo, 11 da produção do biodiesel e 7 da logística e comercialização.

\section{Estrutura do modelo de simulação}

O modelo de simulação permite avaliar a viabilidade econômica de um projeto de produção de biodiesel ou qualquer empreendimento verticalizado para a produção de óleo vegetal + biodiesel ou de oleaginosas + óleo vegetal + biodiesel. Esta avaliação é feita com base nos seguintes indicadores de viabilidade econômica: Valor Presente Líquido (VPL); Taxa Interna de retorno (TIR); Retorno sobre o Investimento; Lucro Líquido Médio e Margem de lucro.

Os resultados financeiros são determinados a partir de fluxos de caixa dependendo basicamente de uma combinação de receitas obtidas com co-produtos, custos de capital, de aquisição de matérias-primas, industriais e logísticos.

A simulação gerou três cenários possíveis (pessimista, provável e otimista) para cada um dos seguintes elos da cadeia: plantio e colheita do grão, extração do óleo e produção do biodiesel. Estes elos foram representados por diferentes fluxos de caixa. Os cenários agrícolas foram 
escolhidos com base na produtividade da oleaginosa (toneladas por hectare). Já o teor de óleo (percentual de óleo produzido por tonelada de grão esmagado) foi a base para os cenários de extração de óleo e o custo industrial por litro a base para os cenários de produção biodiesel.

A ferramenta de simulação permite combinar esses diferentes cenários para estimar o custo do biodiesel na fábrica e na base distribuidora. Este custo é calculado no break even, ponto onde o somatório dos VPLs das receitas e despesas acumuladas em cada ano é nulo ao final do horizonte de planejamento e, portanto, a partir do qual o projeto passa a ser economicamente viável.

Para os casos em que a cadeia é parcialmente verticalizada. onde a produção de óleo vegetal e biodiesel são elaboradas pelo mesmo investidor, o simulador utiliza o preço de mercado do insumo agrícola como ponto de partida para chegar ao custo do óleo e do biodiesel. Nos casos em que o projeto seja só de produção de biodiesel, o ponto de partida da simulação é o preço de compra do óleo.

Além do nível de verticalização, do cenário e dos preços de mercado do insumo agrícola e do óleo vegetal, o modelo considera os seguintes dados de entrada para a simulação: coeficientes técnicos do processo produtivo; grau de ociosidade das fábricas de óleo e biodiesel; rota de produção (metílica ou etílica, conforme o álcool utilizado); preço dos co-produtos, margens de comercialização, alíquotas para impostos e origem da oleaginosa - agricultura familiar ou intensiva (o que determina se haverá algum tipo de redução de impostos).

\section{Cadeia produtiva da soja no Estado da Bahia}

O grão, o óleo e o farelo obtidos a partir da soja são commodities hoje utilizadas para a produção de diversos produtos. O farelo, um co-produto na extração do óleo, é usado principalmente como ração animal devido ao alto teor de proteína.

A soja é um dos principais produtos agrícolas produzidos na Bahia. O produto é o carro chefe da agricultura do Oeste Baiano, que cultiva quase 900 mil hectares de soja, produzindo mais de 2,2 milhões de toneladas do produto na safra 2003/2004 (BAHIA INVEST, 2005). Segundo a Companhia Nacional de Abastecimento (CONAB) apud Rocha (2005), a produção, área colhida e rendimento da soja na Bahia ao longo dos anos são apresentados na Tabela 1.

Tabela 1 - Produção de soja na Bahia

\begin{tabular}{cccc}
\hline Ano / Safra & Produção (ton) & Área Colhida (mil ha) & Rendimento (kg/ha) \\
\hline $1999 / 2000$ & 1.524 .700 & 635,3 & 2.400 \\
$2000 / 2001$ & 1.450 .300 & 690,6 & 2.100 \\
$2001 / 2002$ & 1.464 .000 & 800,0 & 1.830 \\
$2002 / 2003$ & 1.556 .200 & 850,4 & 1.830 \\
$2003 / 2004$ & 2.218 .100 & 821,5 & 2.700 \\
$2004 / 2005$ & 2.349 .000 & 870,0 & 2.700 \\
\hline
\end{tabular}


Neste cenário, a cadeia da soja atrai para a região Oeste da Bahia empresas de porte que movimentam o parque industrial da sojicultura e que processam cerca de 1,65 milhão/toneladas/ano de grãos nas unidades de esmagamento.

\section{Dados utilizados no modelo de simulação}

As seções seguintes apresentam os dados de plantio da soja, extração do óleo e produção do biodiesel utilizados no modelo de simulação.

\subsection{Dados de plantio de soja}

Estudos da Empresa Baiana de Desenvolvimento Agrícola - EBDA - (2005) mostram que a produtividade da soja na Bahia chega a 3 ton/ha, uma das maiores do país. De acordo com dados primários, a produtividade média da soja no oeste baiano em 2005 ficou entre 2,28 ton/ha e 2,7 ton/ha.

No primeiro ano de projeto (Ano 0) são realizados investimentos em ativos fixos. A estrutura de custos adotada neste trabalho considera o investimento inicial em plantio composto por custos com: (1) Aquisição de terreno; (2) Obras civis, instalações prediais, (3) Equipamentos, ferramentas, máquinas e veículos e (4) Outros Custos (Licenças, Alvarás etc). Segundo dados detalhados obtidos em campo, o custo total médio no Ano 0 chega a R $2.310,00 /$ ha.

A partir do segundo ano até o $15^{\circ}$ ano de projeto há custos relacionados ao plantio e à colheita, como: despesas administrativas, materiais e insumos, preparo da área a ser plantada e mãode-obra para plantio, tratos culturais, colheita e beneficiamento. De acordo com dados da EBDA (2005), a média deste custo chega a R \$968,40/ha/ano.

\subsection{Dados de extração de óleo de soja}

Esta seção apresenta os dados referentes à etapa extração de óleo de soja utilizados na simulação. Para determinar os rendimentos do processo de produção de óleo foram comparados dados obtidos em campo com duas empresas da Bahia e dados apresentados em um estudo da Bunge (2004). Os valores adotados para cada cenário são apresentados na Tabela 2. O cenário otimista é o que maximiza a receita. 
Tabela 2 - Cenários de rendimentos do processo de produção de óleo de soja

\begin{tabular}{lccc}
\hline \multicolumn{1}{c}{ Item } & Pessimista & Provável & Otimista \\
\hline Óleo de soja & $17,5 \%$ & $18,5 \%$ & $21,0 \%$ \\
Farelo de soja & $75 \%$ & $78 \%$ & $75 \%$ \\
Casca & $7,5 \%$ & $3,5 \%$ & $4 \%$ \\
\hline
\end{tabular}

Dados primários indicaram um custo operacional da extração de óleo de $\mathrm{R} \$ 17,00$ por tonelada. Este valor inclui os custos industriais e com solvente, mas não considera o custo com a compra de grãos.

Ainda de acordo com dados primários, os itens de custo componentes do custo industrial podem ser assim classificados em ordem decrescente: (1) Combustíveis e energia elétrica, (2) Mãode-obra, (3) Manutenção e conservação de equipamentos, (4) Materiais e Insumos, (5) Despesas administrativas, (6) Impostos e (7) Controle de qualidade.

Em relação ao investimento inicial, de acordo com dados primários, estima-se um custo de $\mathrm{R} \$ 30$ milhões para uma planta com capacidade de processamento de 4.000 ton/dia. Este custo inclui investimentos em obras civis, instalações prediais, além de equipamentos, ferramentas e máquinas necessários ao processo produtivo.

\subsection{Cotações do grão, óleo e farelo de soja}

Por serem commodities, os preços do grão, do farelo e do óleo de soja no Brasil guardam relação direta com os internacionais cotados na Bolsa de Chicago. As cotações anuais médias deste grão na bolsa de Chicago são apresentadas na Tabela 3 (em US\$/ tonelada).

Tabela 3 - Cotação média anual dos grãos, do farelo e do óleo bruto de soja na bolsa de Chicago (em US\$/ton)

\begin{tabular}{cccccccccccccc}
\hline Ano & $\mathbf{1 9 9 3}$ & $\mathbf{1 9 9 4}$ & $\mathbf{1 9 9 5}$ & $\mathbf{1 9 9 6}$ & $\mathbf{1 9 9 7}$ & $\mathbf{1 9 9 8}$ & $\mathbf{1 9 9 9}$ & $\mathbf{2 0 0 0}$ & $\mathbf{2 0 0 1}$ & $\mathbf{2 0 0 2}$ & $\mathbf{2 0 0 3}$ & $\mathbf{2 0 0 4}$ & $\mathbf{2 0 0 5}$ \\
\hline Grão & 226 & 245 & 220 & 279 & 294 & 234 & 179 & 190 & 174 & 190 & 216 & 280 & 238 \\
Farelo & 192 & 186 & 173 & 243 & 268 & 167 & 144 & 176 & 183 & 176 & 191 & 226 & 199 \\
Óleo bruto & 416 & 546 & 596 & 535 & 530 & 609 & 441 & 335 & 306 & 402 & 496 & 549 & 462 \\
\hline
\end{tabular}

Fonte: Secretaria de Comércio Exterior (SECEX) apud ABIOVE, 2006

A média das cotações apresentadas na tabela 3 é igual a 228,00; 194,15 e 478,70 US\$/tonelada para o grão, o farelo e o óleo de soja, respectivamente. Considerando a cotação do dólar de $\mathrm{R} \$ 2,15$, o preço médio da tonelada é igual a $\mathrm{R} \$ 490,50, \mathrm{R} \$ 417,54$ e $\mathrm{R} \$ 1.029,50$ para o grão, o farelo e o óleo de soja, respectivamente.

A tonelada de casca foi considerada igual a $\mathrm{R} \$ 165,00$, cotação esta obtida em campo. 
Fazendo-se uma análise de regressão do grão e do farelo obteve-se um R-Quadrado igual a 0,998175, o que mostra a forte correlação entre estas 2 variáveis. Em forma de equação, a regressão obtida é: Preço/ton de grão $=1,07 *$ Preço/ton de farelo. Esta equação foi usada na simulação da cadeia totalmente verticalizada da soja.

\subsection{Dados de produção de biodiesel}

Os custos de investimentos e produção de biodiesel utilizados na simulação consideram três diferentes fontes de estudo. Os dados destas diferentes fontes formaram cenários - onde cada fonte constitui um cenário - de acordo com o custo total por litro obtido em cada estudo, conforme apresentado na Tabela 4. Assim, os dados do estudo de Jordão Filho (2004) são usados para o cenário pessimista, os de Cosenza (2005) para o cenário provável e os da Dedini (2006a) para o cenário otimista.

Tabela 4 - Comparação de custos de produção de biodiesel

\begin{tabular}{cccc}
\hline Capacidade (milhões de litros/ano) & $\mathbf{6 0}$ & $\mathbf{8 2}$ & $\mathbf{1 0 0}$ \\
\hline Custo Operacional (R \$/litro) & 0,22 & 0,15 & 0,12 \\
Custo de Capital (R\$/litro) & 0,06 & 0,04 & 0,03 \\
Custo Total (R\$/litro) & 0,29 & 0,19 & 0,16 \\
\hline Fonte: & \multirow{2}{*}{ JORDÃO FILHO, 2004 } & COSENZA, 2005 & DEDINI, 2006a
\end{tabular}

Os coeficientes técnicos e preços dos insumos e co-produtos do processo de transesterificação utilizados na simulação são apresentados na Tabela 5.

Tabela 5 - Coeficientes técnicos e preços dos insumos

\begin{tabular}{|c|c|c|c|c|}
\hline \multirow{2}{*}{ INSUMOS } & \multicolumn{2}{|c|}{ Preço (R\$/litro) } & \multicolumn{2}{|c|}{ Consumo (\% do biodiesel produzido) } \\
\hline & Rota Etílica & Rota Metílica & Rota Etílica & Rota Metílica \\
\hline Óleo Vegetal & $\mathrm{R} \$ 1,03$ & $\mathrm{R} \$ 1,03$ & $95,4 \%$ & $99,5 \%$ \\
\hline Álcool & $\mathrm{R} \$ 0,90$ & $\mathrm{R} \$ 0,77$ & $14 \%$ & $10,3 \%$ \\
\hline Catalisador & $\mathrm{R} \$ 3,50$ & $\mathrm{R} \$ 3,50$ & $0,05 \%$ & $0,05 \%$ \\
\hline \multirow{2}{*}{ CO-PRODUTOS } & \multicolumn{2}{|c|}{ Preço (R\$/litro) } & \multicolumn{2}{|c|}{ Produção (\% de biodiesel produzido) } \\
\hline & Rota Etílica & Rota Metílica & Rota Etílica & Rota Metílica \\
\hline Glicerina & $\mathrm{R} \$ 1,65$ & $\mathrm{R} \$ 1,65$ & $9,35 \%$ & $9,75 \%$ \\
\hline Ácidos Graxos & $\mathrm{R} \$ 0,00$ & $\mathrm{R} \$ 0,00$ & $0,10 \%$ & $0,10 \%$ \\
\hline
\end{tabular}

Fonte:

JORDÃO FILHO, 2004; MB DO BRASIL, 2006 e

UNIAMÉRICA ONLINE, 2006

JORDÃO FILHO, 2004 e

DORNELES,2005

\section{Resultados obtidos e análise dos resultados}


Conforme descrito anteriormente, o modelo de simulação trabalhou com 3 cenários (pessimista, provável e otimista) para cada um dos 3 elos analisados da cadeia (plantio e colheita do grão, extração de óleo e produção de biodiesel). Além disso, há 3 diferentes níveis de verticalização: 1) apenas a produção de biodiesel; 2) a produção de óleo vegetal e de biodiesel; e 3) a produção de oleaginosas, de óleo vegetal e de biodiesel em um único empreendimento. Pela combinação desses itens, é possível realizar 39 simulações para a cadeia do biodiesel produzido a partir da soja.

Considerando as demais variáveis, como alíquotas para impostos, custo de capital, preço dos insumos e co-produtos, graus de ociosidade das fábricas, custos logísticos e margens de comercialização, há inúmeras outras possibilidades de simulação para esta cadeia produtiva. Em função do escopo deste artigo, os resultados apresentados nesta seção consideram as seguintes delimitações:

- Cenário de biodiesel: simulou-se somente o cenário provável de biodiesel, que corresponde a um custo industrial de $\mathrm{R} \$ 0,19$ por litro.

- Grau de ociosidade de 20\%, para a fábrica de biodiesel (grau médio das empresas do setor de energia) e de $16,67 \%$ para a de óleo de soja na Bahia (dado obtido em campo).

- Rota de produção: metílica, pois a maioria das usinas em operação no mundo atualmente considera esta rota de produção.

- Localização da fábrica de óleo soja: no Oeste baiano - próximo à região produtora. Essa escolha se justifica, pois: já existe capacidade instalada para processamento dos grãos no próprio Oeste; facilita o rastreamento da produção de soja transgênica; diminui a tonelagem de transporte, já que a casca não será transportada.

- Localização da fábrica de biodiesel: no Recôncavo. Como a rota adotada na simulação foi a metílica, a localização da fábrica de biodiesel no Recôncavo é a melhor opção, pela proximidade com a Metanor (única empresa baiana produtora de metanol) e com a base de distribuição de combustíveis da Petrobrás, localizada em São Francisco do Conde.

- Custo de transporte: de acordo com dados primários, o custo por km de um caminhão tanque de $30 \mathrm{~m} 3$ é aproximadamente igual ao custo do diesel (adotado como R $\$ 1,60$ / litro neste estudo). Como a distância aproximada do Oeste ao Recôncavo é de 929 km, o custo com frete é igual $\mathrm{R} \$ 0,10$ por litro de biodiesel.

- Margens de comercialização iguais a zero e custo de capital de $10 \%$.

- Como a cultura da soja no Oeste Baiano é 100\% intensiva, de acordo com Dorneles (2005), o total de tributos incidentes na produção de biodiesel é de R\$0,222/ litro, mais o ICMS. Segundo dados do Sindicato das distribuidoras de combustíveis apud Dedini (2006b), a alíquota de ICMS para a comercialização do biodiesel na Bahia é de 17\%. 
A Tabela 6 apresenta os resultados das simulações para a cadeia totalmente verticalizada (plantio de oleaginosa + extração do óleo + produção de biodiesel) e semi-verticalizada (produção de óleo + biodiesel). São mostrados os custos por tonelada de grãos e por litro de óleo de soja, de biodiesel na fábrica e na base no break-even. $\mathrm{O}$ custo do biodiesel na base de distribuição é igual ao custo do mesmo na fábrica mais o ICMS.

Tabela 6 - Resultados das simulações para a cadeia totalmente verticalizada

\begin{tabular}{cc|c|c|cc}
\hline \multicolumn{2}{c|}{ Cenário } & $\begin{array}{c}\text { \$Grãos } \\
\text { (ton) }\end{array}$ & $\begin{array}{c}\text { \$ Óleo } \\
\text { (litro) }\end{array}$ & $\begin{array}{c}\text { \$Biodiesel } \\
\text { Fábrica (l) }\end{array}$ & $\begin{array}{c}\text { \$Biodiesel } \\
\text { Base (l) }\end{array}$ \\
\hline Pessimista & Pessimista & $\mathrm{R} \$ 677,05$ & $\mathrm{R} \$ 1,22$ & $\mathrm{R} \$ 1,74$ & $\mathrm{R} \$ 2,03$ \\
Pessimista & Provável & $\mathrm{R} \$ 677,05$ & $\mathrm{R} \$ 1,09$ & $\mathrm{R} \$ 1,61$ & $\mathrm{R} \$ 1,88$ \\
Pessimista & Otimista & $\mathrm{R} \$ 677,05$ & $\mathrm{R} \$ 1,04$ & $\mathrm{R} \$ 1,56$ & $\mathrm{R} \$ 1,83$ \\
Provável & Pessimista & $\mathrm{R} \$ 571,73$ & $\mathrm{R} \$ 1,04$ & $\mathrm{R} \$ 1,56$ & $\mathrm{R} \$ 1,83$ \\
Provável & Provável & $\mathrm{R} \$ 571,73$ & $\mathrm{R} \$ 0,93$ & $\mathrm{R} \$ 1,45$ & $\mathrm{R} \$ 1,70$ \\
Provável & Otimista & $\mathrm{R} \$ 571,73$ & $\mathrm{R} \$ 0,89$ & $\mathrm{R} \$ 1,41$ & $\mathrm{R} \$ 1,65$ \\
Otimista & Pessimista & $\mathrm{R} \$ 497,55$ & $\mathrm{R} \$ 0,91$ & $\mathrm{R} \$ 1,43$ & $\mathrm{R} \$ 1,67$ \\
Otimista & Provável & $\mathrm{R} \$ 497,55$ & $\mathrm{R} \$ 0,82$ & $\mathrm{R} \$ 1,34$ & $\mathrm{R} \$ 1,57$ \\
Otimista & Otimista & $\mathrm{R} \$ 497,55$ & $\mathrm{R} \$ 0,79$ & $\mathrm{R} \$ 1,31$ & $\mathrm{R} \$ 1,53$ \\
------- & Pessimista & ------- & $\mathrm{R} \$ 0,90$ & $\mathrm{R} \$ 1,42$ & $\mathrm{R} \$ 1,66$ \\
------- & Provável & ------- & $\mathrm{R} \$ 0,81$ & $\mathrm{R} \$ 1,33$ & $\mathrm{R} \$ 1,56$ \\
------- & Otimista & ------- & $\mathrm{R} \$ 0,78$ & $\mathrm{R} \$ 1,30$ & $\mathrm{R} \$ 1,52$ \\
\hline
\end{tabular}

No caso da cadeia desverticalizada (apenas para produção de biodiesel), o custo do biodiesel na fábrica chega a $\mathrm{R} \$ 1,55$ por litro, e na base a $\mathrm{R} \$ 1,81$ por litro.

\section{Conclusões}

Até o momento já foram realizados cinco leilões de biodiesel no Brasil, como objetivo garantir aos produtores de biodiesel e aos agricultores, especialmente os que praticam agricultura familiar, um mercado para a venda da produção. A menor oferta vencedora foi de $\mathrm{R} \$ 1,74$ por litro. Comparando este preço ao do biodiesel de óleo de soja na fábrica, todos os 13 cenários analisados levam a uma produção de biodiesel a preços inferiores ao valor mínimo do leilão, mostrando a competitividade da cadeia produtiva da soja na Bahia.

Pela área cultivável brasileira atual, a soja é a oleaginosa de maior oferta e se apresenta como a melhor opção para a produção de biodiesel a curto prazo. Na Bahia, a área plantada é de 870 mil ha., o que corresponde a uma produção de 2,35 milhões de toneladas de grãos. Além disso, a capacidade de extração no oeste baiano (400 milhões de litros de óleo/ano) poderia atender à 50\% da demanda brasileira de B2 em 2008 (800 milhões de litros).

Por fim, deve-se destacar ainda que a desoneração tributária em todos os elos da cadeia produtiva é um fator fundamental para que o preço do biodiesel possa ser competitivo ao diesel de 
petróleo, além de permitir as margens adequadas para os produtores. Considerando-se a desoneração total de impostos, obteve-se um custo de biodiesel num cenário provável da cadeia totalmente verticalizada de $\mathrm{R}$ \$1,23/ litro, na base de distribuição, o que representa uma variação de $27,65 \%$ em relação ao valor obtido para a cadeia tributada. Este preço não somente seria comparável ao do diesel de petróleo, mas também seria competitivo em nível internacional. Segundo Bockey e von Schenck (2006), o preço do biodiesel na usina na Alemanha variou entre R\$ 1,82 e R\$ 1,96 entre 2004 e 2005, o que comprova a possibilidade de exportação do biodiesel produzido a partir do óleo de soja na Bahia.

Agradecimentos ao CNPq (479377/2006-5; 301887/2006-3) e a CAPES (bolsa Mestrado).

\begin{abstract}
The renewable energies have been considered very imported in political and economic discussions in the World. In spite of being the biodiesel deeply investigated, regional characteristics of this biofuel have not been enough analyzed. Thus, this paper analyzes the economic feasibility of productive chain of biodiesel produced from soybean oil in Bahia, based on a simulation model developed by the authors. 13 scenarios were simulated for biodiesel production. The results analysis pointed to the competitiveness of this productive chain in Bahia.
\end{abstract}

Key-words: biodiesel; productive chain; economic evaluation, soybean.

\title{
Referências
}

ABIOVE - Associação Brasileira da Indústria de Óleos Vegetais. Exportações do Complexo Soja, 2006. Disponível em http://www.abiove.com.br/export.html. Acesso em março de 2006.

ANSELMO FILHO, P., BADR, O. Biomass resource for energy in North-Eastern Brazil. Applied Energy, Volume 77, p 51-67, 2004. cross $^{\text {ref }}$

BAHIA INVEST. Disponível em http://www.bahiainvest.com.br. Acesso em julho de 2005.

BOCKEY, D. \& VON SCHENCK, W. Biodiesel: Production and Marketing in Germany 2005. UFOP - Union zur Förderung von Oel - und Proteinpflanzen e. V. (Union for the Promotion of Oil and Protein Plants), 2006.

BUNGE ALIMENTOS (2004). Disponível em www.bunge.com.br/download/fatos/bunge_fato_22062004.pdf. Acesso em março de 2006.

COSEnZA, C. A. N. Estudo de Localização de Pólos de Produção de Biodiesel no Semi-árido Nordestino. Relatório Técnico, COPPE, 2005.

DEDINI - Indústria de Base (2006a). Apresentação do Seminário: Investimentos em Biodiesel. Disponível em http://www.bndes.gov.br/conhecimento/seminario/Biodiesel_DEDINI.pdf. Acesso em abril de 2006.

DEDINI - Indústria de Base (2006b). I Simpósio do Agronegócio de Plantas Oleaginosas. Disponível em http://www.ciagri. usp.br/ simpol/downloads/14\%20DEDINI.pdf...\%22DEDINI\%20biodiesel\%20pdf\%22. Acesso em julho de 2006.

DEMIRBAS, M.F., BALAT, M. Recent advances on the production and utilization trends of bio-fuels: A global perspective. Energy Conversion and Management, Volume 47, Número 15-16, p. 2371-238, 2006.

DORNELES, R. Palestra de Apresentação do Programa Nacional de Produção e Uso de Biodiesel, Ministério de Minas 
e Energia (MME), 2005. Disponível em http://www.biodiesel.gov.br/rede.html. Acesso em dezembro de 2005.

EBDA - Empresa Baiana de Desenvolvimento Agrícola. Estudo de Custo de Produção de Oleaginosas, 2005.

FERNANDO, S., KARRA, P., HERNANDEZ, R., KUMAR JHAA, S. Effect of incompletely converted soybean oil on biodiesel quality. Energy, Volume 32, p. 844-851, 2007. cross $^{\text {ref }}$

GOLDEMBERG, J., TEIXEIRA COELHO, S., NASTARI, P.M., LUCON, O. Ethanol learning curve-the Brazilian experience. Biomass and Bioenergy, Volume 26, Número 3, p. 301-304, 2004.

GRANOL (2005). Disponível em http://www.granol.com.br/FOLDER.pdf. Acesso em março de 2006.

JORDÃO FILHO, W. Implementação de negócios de biodiesel no Brasil: Estudo de viabilidade técnica e financeira preliminar, 2004.

LUND, H. Renewable energy strategies for sustainable development. Energy, Volume 32, Número 6, p. 912-919, 2007

$\begin{array}{llll}\text { MB DO } & \text { BRASIL } & \text { (2006). Disponível }\end{array}$

http://www.mbdobrasil.com.br/html/modules.php?name=News\&file=article\&sid=936. Acesso em janeiro de 2006.

MCKENDRY, P. Energy production from biomass (part 1): overview of biomass. Bioresource Technology, Volume 83, Número 1, maio 2002, p. 37-46, 2002.

MCT - Ministério de Ciência e Tecnologia. Lei No. 11.097, de 13.01.2005. Disponível em http://www.mct.gov.br/legis/leis/11097_2005.htm. Acesso em julho de 2005.

MEIRELlES, F. S. Biodiesel: Informe Departamento Econômico FAESP, n. 67, 2003. Disponível em: http://www.faespsenar.com.br/faesp/economico/EstArtigos/biodiesel.pdf. Acesso em junho de 2005.

MENON, A; BHARADWAJ, S.G.; ADIDAM, P.T. \& EDILSON, S.W. Antecedents and Consequences of Marketing Strategy Making: A Model and a Test Journal of Marketing, v. 63, n.2, p. 18-40, 1999.

PARENTE, E. J. S. Biodiesel: uma aventura tecnológica num país engraçado. Fortaleza: Tecbio, 2003.

ROCHA, H. M. A Produção de Oleaginosas na Bahia e sua Inserção no Programa Biodiesel. Secretaria de Agricultura da Bahia. Disponível em http://www.seagri.ba.gov.br/palestra_oleoginosas.pdf. Acesso em setembro de 2005.

ROZAKIS, S., SOURIE, J. -C. Micro-economic modelling of biofuel system in France to determine tax exemption policy under uncertainty. Energy Policy, Volume 33, p. 171-182, 2005.

UNIAMÉRICA ONLine (2006). Annual Average Prices of Selected Oils and Fats: 1975 - 2004. Disponível em http://www.uniamericabrasil.com.br/portugues/estatisticas_6.php. Acesso em maio de 2006.

YIN, R. Estudo de Caso: planejamento e métodos. São Paulo: Bookman, $3^{\mathrm{a}}$ ed., 2005.

\section{Dados completos dos autores:}

Nome completo: Adriana Leiras

Filiação institucional: Pontifícia Universidade Católica do Rio de Janeiro (PUC-Rio)

Departamento de Engenharia Industrial (DEI)

Função: Doutoranda do DEI e Pesquisadora do Núcleo de Excelência em Otimização (NEXO) da PUC-Rio 
Endereço completo: Rua Marquês de São Vicente, 225, Gávea - Sala: 952L - CEP 22543-900

Rio de Janeiro - RJ - Brasil

Telefones para contato: (21) 3527-2111 ou (21) 3527-1287

E-mail: aleiras@aluno.puc-rio.br

Nome completo: Silvio Hamacher

Filiação institucional: Pontifícia Universidade Católica do Rio de Janeiro (PUC-Rio)

Departamento de Engenharia Industrial (DEI)

Função: Professor do DEI e Coordenador do Núcleo de Excelência em Otimização (NEXO) da PUC-Rio

Endereço completo para correspondência (bairro, cidade, estado, país e CEP): Rua Marquês de São Vicente, 225, Gávea - Sala: 952L - CEP 22543-900 - Rio de Janeiro - RJ - Brasil

Telefones para contato: (21) 3527-2111 ou (21) 3527-1287

E-mail: hamacher@puc-rio.br

Nome completo: Luiz Felipe Roris Rodriguez Scavarda do Carmo

Filiação institucional: Pontifícia Universidade Católica do Rio de Janeiro (PUC-Rio)

Departamento de Engenharia Industrial (DEI)

Função: Professor do DEI e Pesquisador do Núcleo de Excelência em Otimização (NEXO) da PUC-Rio

Endereço completo: Rua Marquês de São Vicente, 225, Gávea - Sala: 952L - CEP 22543-900 Rio de Janeiro - RJ - Brasil

Telefones para contato: (21) 3527-2111 ou (21) 3527-1287

E-mail:liscava@puc-rio.br

Recebido para publicação em: 21/11/2007

Aceito para publicação em: 03/12/2007 